\title{
Aspectos legales del Polo Turístico Golfo de Papagayo, Guanacaste, Costa Rica: régimen especial
}

\author{
María Virginia Cajiao \\ Consultora legal ambiental, San José, Costa Rica: vicky.cajiao@gmail.com \\ Recibido 21-III-2011. Corregido 31-XII-2011. Aceptado 29-II-2012.
}

\begin{abstract}
Legal aspects of the Golfo de Papagayo Tourist Project, Guanacaste, Costa Rica: special regime. The Gulf of Papagayo, Guanacaste, Costa Rica,area is the main center of tourist development in Costa Rica. The Gulf of Papagayo Project (GPP) is the product of a study contracted by the Central American Bank for Economic Integration (CABEI) to determine the tourist potential of Central America. This project started in 1982, and was excempted from the Municipal administration and handed over to the Costa Rica Tourist Board (ICT by its Spanish name). The GPP intends a planned development by means of a Master Plan that is adminitered and supervised by the central government. It is a proyect declared of public utility and national convinience which givges it more support. With its master plan since 1995 that defines the general guidelines and its special legislation, this project has been carried out over the years as an oportunity for Guanacaste and Costa Rica. Rev. Biol. Trop. 60 (Suppl. 2): 225-230. Epub 2012 April 01.
\end{abstract}

Key words: Papagayo, Costa Rica, legal regime, public zone, Bahía Culebra.

El Polo Turístico Golfo de Papagayo, ubicado en el Norte del Pacífico costarricense, se identifica como zona de riqueza escénica y cultural de mayor potencial turístico del istmo centroamericano, con base en estudios publicados por el Banco Centroamericano de Integración Económica (BCIE) en 1965-1970. Como zona especial cuenta con un régimen de excepción dado la significancia y lo estratégico del proyecto para el país.

El objetivo de este artículo es guiar al lector (de una forma descriptiva) de las regulaciones específicas que existen como régimen de excepción para este proyecto a través de un recorrido cronológico de la legislación nacional que para el efecto se ha aprobado.

\section{Turismo: industria de utilidad pública}

Resulta importante para iniciar y comprender el contexto de este proyecto considerar que en diciembre de 1960 se declara en Costa Rica "el turismo" industria de utilidad pública bajo la Ley número 2.706. Como parte de esa declaratoria se establece un impuesto a favor del Instituto Costarricense de Turismo (ICT) del 3\% sobre la suma cobrada diariamente a los pasajeros por habitación en las instalaciones turísticas respectivas.

Cinco años más tarde, el Banco Centroamericano de Integración Económica (BCIE) publica un estudio para un plan de turismo en Centroamérica. Es así como en 1970 se inicia con el proceso de identificar las zonas con mayor potencial, en el cual el Golfo de Papagayo se destacó por ser una zona con riquezas desde el punto de vista geográfico, cultural, escénico y de alta biodiversidad. En 1974, la firma contratada por el BCIE realizó un estudio para analizar el potencial turístico de Centroamérica y determinó lo que sería el Programa Promocional y financiero del Turismo 
en Centroamérica, cuyo objetivo era adoptar un Programa de Desarrollo Regional para la atracción de un turismo internacional de tipo masivo y vacacional.

\section{Ley sobre la Zona Marítimo Terrestre}

Para 1977 se publica la actual Ley sobre la Zona Marítimo Terrestre, ley número 6043, que regula, entre otros, la franja costera de doscientos metros de ancho a todo lo largo de los litorales Pacífico y Caribe indicando que esta zona constituye parte del patrimonio nacional, pertenece al Estado y es inalienable e imprescriptible. Esta ley estipula que le corresponde al Instituto Costarricense de Turismo en nombre del Estado la superior y general vigilancia en todo lo referente a la zona marítimo terrestre. Importante aclarar que ésta no es la primer ley que regula el tema pero si la que consolida legalmente el concepto de la franja de doscientos metros en ambos litorales.

Por su parte, el artículo 3 de este cuerpo jurídico establece que el usufructo y administración de la zona marítimo terrestre le pertenece a la Municipalidad de la jurisdicción respectiva, y ese ente es el único competente para otorgar concesiones en las zonas restringidas.

Sin embargo, se establecen algunas excepciones para casos especiales, de manera que en el artículo 74 de esta Ley se indica que las áreas afectadas del Proyecto de Desarrollo Integral de la Bahía Culebra (como originalmente se le llamó - más tarde Papagayo) quedarán bajo la administración directa del ICT. Dejando en manos del Poder Ejecutivo la reglamentación que regirá ese desarrollo, sin perjuicio del usufructo y cánones que correspondan a las municipalidades respectivas conforme a esta ley (Ley número 6043 del 2 de marzo de 1977).

\section{UTILIDAD PÚBLICA}

En 1979, los bienes inmuebles (fincas, derechos o intereses patrimoniales legítimos) necesarios para realizar y ejecutar el proyecto turístico en Bahía Culebra, son declarados de utilidad pública por medio de la Ley número
6379. Este mismo cuerpo normativo autoriza al ICT para adquirir de forma directa dichos bienes localizados en la zona marítima del litoral Pacífico ubicada desde Punta Cabuya al norte, hasta un kilómetro al sur de Punta Ballena. Lo anterior con exclusión de la zona pública, área de uso común y libre tránsito, vedada - en principio - al uso particular o privativo. El resto de terrenos de titularidad pública, que el Estado traspasó, a título gratuito, al Instituto Costarricense de Turismo, a nombre de quien se hallan inscritos en el Registro de la Propiedad Inmueble, están destinados al otorgamiento de concesiones, con base en el trámite del Reglamento a la Ley sobre la Zona Marítimo Terrestre (Decreto Ejecutivo número 7841-P del 16 de diciembre de 1977, artículo 93) y al Reglamento a la Ley número 6758, Ley Reguladora del Desarrollo y Ejecución del Proyecto Turístico Golfo de Papagayo, del 6 de mayo de 1982.

\section{Ley reguladora del desarrollo y ejecución del proyecto turístico Golfo de Papagayo}

Esta Ley regula el desarrollo y ejecución del proyecto turístico indicando que únicamente deberán llevarse a cabo las obras previstas en el Plan Maestro, aprobado por el ICT, así como a las disposiciones normativas pertinentes y de acuerdo con las normas técnicas que este instituto emita al efecto.

En 1995, la Junta Directiva del ICT aprueba el Plan Maestro General del Proyecto Turístico Golfo de Papagayo, el cual comprende la regulación de los usos del suelo, una zonificación, la vialidad, las densidades, bases para el diseño de sitio y especificaciones generales para el desarrollo del proyecto. (ICT, Sesión Ordinaria de Junta Directiva $\mathrm{N}^{\circ} 4572$, inciso VIII, celebrada el 10 de julio de 1995.)

En este Plan Maestro se establecen los siguientes principios orientadores del desarrollo del Proyecto:

a. Respeto total a las áreas protegidas;

b. manejo adecuado de la cobertura vegetal existente; 
c. distribución espacial equilibrada de las instalaciones y construcciones;

d. facilitación de las circulaciones internas, adaptadas a la topografía;

e. óptimo aprovechamiento de vistas panorámicas;

f. reducción y control de posibilidades de contaminación;

g. aprovechamiento de materiales autóctonos, incluyendo vegetación;

h. fomento del uso de energías alternativas;

i. reciclaje de aguas servidas y de desechos sólidos;

j. diseños arquitectónicos y acabados externos adecuados a la zona y a la finalidad del Proyecto;

k. libre uso de playas y acceso a vistas panorámicas.

1. Los titulares de las concesiones dentro del Polo Turístico Golfo de Papagayo podrán adoptar estipulaciones previa aprobación del ICT, para regular la dirección, operación y mantenimiento de su concesión como una comunidad planificada, en las cuales se constituya organizaciones maestras administradoras de los servicios generales comunales y de las áreas comunes, así como regulaciones operativas obligatorias para los miembros de esa comunidad (Así adicionado el inciso anterior en sesión $\mathrm{N}^{\circ} 5317$ de 3 de agosto de 2004).

En general, el Proyecto Papagayo debe orientarse dentro del marco del ordenamiento vigente, de sus fines, de los intereses nacionales y regionales, y dentro de los principios del desarrollo sostenible, en armonía con la naturaleza indica el Plan Maestro.

Dentro de las restricciones específicas que esta ley contempla establece:

- como máximo de construcción en todo el proyecto 26.450 habitaciones (que incluye hotel, vivienda en condominio y vivienda unifamiliar, sin superar 20 habitaciones promedio por hectárea,

- mantener un coeficiente de ocupación de superficie no mayor al $30 \%$,
- los cables eléctricos y telefónicos deben ser subterráneos,

- la iluminación externa debe colocarse a poca altura y ser lo menos intensa posible,

- la altura de los edificios no puede ser mayor de tres pisos (14 metros del nivel del terreno natural),

- es prohibido instalar tanques sépticos y tirar desechos al mar, todo proyecto deberá conectar sus aguas residuales a una planta de tratamiento

- y debe respetar las restricciones fundadas en razones arqueológicas y cualquier otro derivado del ordenamiento vigente.

\section{Oficina Ejecutora}

Para la ejecución y desarrollo del proyecto, el ICT crea una Oficina Ejecutora (órgano con desconcentración máxima) integrada por un Consejo Director integrado por el sector privado y representantes del ICT, una Dirección Ejecutiva y el personal adicional necesario. Dicha oficina ejecutora está adscrita al ICT y depende de su Junta Directiva, sus funciones son de dirección, fiscalización y recomendación. Las responsabilidades del Consejo Director (según Decreto Ejecutivo número 35962-MP-TUR) son las siguientes:

a. Revisar y ajustar periódicamente el Plan Maestro, recomendando a la Junta Directiva la aprobación de las modificaciones que fueren necesarias, con la correspondiente publicación en La Gaceta.

b. Recomendar a la Junta Directiva el dictado o la reforma de los reglamentos de operación del Proyecto.

c. Autorizar, previo dictamen técnico y jurídico, la realización de concursos públicos para la adjudicación de áreas libres en el Proyecto Turístico Golfo de Papagayo.

d. Aprobar los planes de desarrollo propuestos por los concesionarios para la adecuada ejecución de su concesión.

e. Recomendar a la Junta Directiva, con fundamento en los criterios técnico y legal, el otorgamiento, prórroga, cesión, gravamen, 
traspaso en fideicomiso, sometimiento en condominio o al régimen de sociedad de inversión, cancelación, extinción y el rescate de concesiones.

f. Establecer el monto del canon que se debe pagar al ICT por concepto del otorgamiento de la concesión y para todos aquellos otros actos dispuestos en el presente reglamento.

g. Aprobar el presupuesto de la Oficina Ejecutora, así como sus modificaciones.

h. Fiscalizar el trabajo de la Dirección Ejecutiva. Ejercer la potestad disciplinaria sobre el Director Ejecutivo y el personal contratado con cargo al fondo especial previsto en el artículo 7 de la Ley número 6758. En ausencia de normativa específica se aplicará supletoriamente el régimen disciplinario del Instituto.

i. Emitir la normativa interna que regule su actividad y funcionamiento como órgano colegiado.

j. Todas las que se deriven del marco jurídico que regula el Proyecto Turístico Golfo de Papagayo.

En cuanto a las concesiones sobre el uso de las tierras del proyecto, éstas serán otorgadas por la Junta Directiva del ICT con base en las recomendaciones que el Consejo Director emita, siempre y cuando sea en respeto del Plan Maestro del Proyecto Papagayo.

Por medio del Decreto Ejecutivo número 25439-MP-TUR del 27 de agosto de 1996 y publicado en La Gaceta del 11 de setiembre de 1996, reformado por el Decreto Ejecutivo número 35962 MP-TUR del 12 de abril del 2010 y publicado en La Gaceta del 28 de mayo del 2010, se reglamenta la Ley para el desarrollo y ejecución del proyecto turístico Golfo de Papagayo. Este reglamento, cumple con la necesidad de regular aquellos aspectos de mayor relevancia para una mejor claridad en el otorgamiento de las concesiones y para el desarrollo mismo de cada uno de los proyectos que se propongan los concesionarios.

Básicamente estas normas otorgan la potestad al ICT para otorgar las condiciones de las concesiones del Proyecto Turístico Golfo
Papagayo y para ejercer el control y vigilancia sobre el mismo. Sin embargo, en estos casos el canon aun corresponde a la Municipalidad respectiva (Liberia y Carrillo). Por su parte, el Dictamen C-171-93 de la Procuraduría General de la República establece que la administración de la porción territorial de la zona marítimo en dicho proyecto compete al ICT con exclusión del régimen Municipal. Sin embargo aclara que subsiste la aplicación de la Ley sobre la Zona Marítimo Terrestre, en lo que sea compatible y no contradiga la regulación especial. Lo anterior sin perjuicio de las competencias de otro orden que puede ostentar la Municipalidad, como por ejemplo el tema de los permisos de construcción.

Por su parte el Dictamen C-028-94 de la Procuraduría General de la República, establece que tratándose de potestades de autotutela y medidas de conservación y defensa de la zona marítimo terrestre según los artículos 13 y 17 de la Ley sobre la Zona Marítimo Terrestre, estas son resorte del ICT.

Las siguientes estipulaciones generales rigen para el otorgamiento de las concesiones:

a. Se podrán otorgar a personas físicas, nacionales o extranjeras. En cuanto a personas jurídicas solo se otorgarán concesiones a entidades constituidas y domiciliadas en el país, cuyos representantes acrediten su solvencia moral y económica.

b. Se otorgan previo concurso, cuyo cartel debe ser publicado en la Gaceta y en un periódico de circulación nacional.

c. Se otorgan a aquellos proyectos que sean más convenientes para los intereses del país.

d. Su plazo máximo es de 50 años, prorrogables por períodos iguales, sin embargo el nuevo plazo deberá justificarse en las necesidades del proyecto y ser acorde al mismo, todo siempre y cuando el concesionario mantenga los requisitos exigidos para ello, conforme a las obligaciones establecidas en la concesión y conforme a las leyes y reglamentos que rigen el Polo Turístico Golfo de Papagayo; si el área y 
sus edificaciones e instalaciones se mantienen en buen estado de conservación; si está al día en el cumplimiento de sus obligaciones contractuales y normativas y salvo que el interés público justifique el rescate de la concesión conforme a lo dispuesto por el artículo quince de la Ley Reguladora de este Polo Turístico. No podrá solicitarse la prórroga del plazo si al menos no ha transcurrido la mitad del plazo otorgado originalmente.

e. Pago de la concesión al ICT.

f. Pago de canon previsto en el artículo 48 de la Ley sobre la Zona Marítimo Terrestre y 49 del reglamento de esa ley a la respectiva Municipalidad.

g. Los adjudicatarios deben rendir una garantía del 5\% del valor estimado de cada etapa del proyecto.

Resulta de importancia aclarar lo ya indicado por la Procuraduría General de la República, al señalar que la normativa del Proyecto Turístico del Golfo de Papagayo es especial, y constituye un régimen de excepción frente al resto del ordenamiento jurídico vigente, el que resulta aplicable, en lo compatible. En tanto no riña con aquella, persiste la legislación sobre la zona marítima terrestre (Véase Dictamen de la Procuraduría General de la República C-17193, C-106-95 y C-151-97).

\section{Conveniencia Nacional}

En el 2005, el desarrollo y ejecución del Proyecto Turístico Golfo de Papagayo es declarado de conveniencia nacional por medio del Decreto Ejecutivo número 33132.

La Ley Forestal, número 7575 del 13 de febrero de 1996, en su artículo 3 define las actividades de conveniencia nacional como aquellas realizadas por las dependencias centralizadas del Estado, las instituciones autónomas o la empresa privada, cuyos beneficios sociales sean mayores que los costos socio-ambientales, cuyo balance debe realizarse mediante los instrumentos apropiados.
Las justificaciones para la declaratoria de dicho Proyecto Turístico en particular de acuerdo con el Decreto Ejecutivo mencionado, radican en que la actividad turística se ha convertido en la principal fuente de divisas para el país y una fuente importante de empleo para los costarricenses, siendo que a su vez el mismo se ha convertido en el principal polo de desarrollo turístico de toda Centroamérica. Asimismo, la Procuraduría General de la República por medio del dictamen C-210-2002 ha recalcado que por Ley el uso del suelo dicho proyecto es turístico, prevaleciendo este sobre cualquier otro tipo de uso.

Se señala de igual forma que los lineamientos establecidos en el Plan Maestro del Proyecto hacen de éste un modelo de desarrollo turístico sostenible al establecer un desarrollo debidamente planificado, bajo la administración y supervisión Estatal.

Como parte de esta declaratoria de conveniencia nacional, y para el óptimo desarrollo del proyecto, se insta a todas las dependencias del Gobierno, ministerios e instituciones públicas, para que brinden toda la ayuda y colaboración al mismo en el marco de sus competencias y posibilidades materiales.

\section{Interés Prioritario de Investigación}

En el 2005, mediante Decreto Ejecutivo número 32051-MINAE se declara de interés prioritario el desarrollo de proyectos de investigación, protección y educación ambiental, en procura de la conservación y uso racional de los recursos marinos existentes en el Golfo de Papagayo y sus zonas de influencia. Según este decreto el Sistema Nacional de Áreas de Conservación como sistema de gestión y coordinación institucional, desconcentrado y participativo realizará acciones para fomentar la participación social en el manejo y protección de los ecosistemas costero-marino en el Golfo de Papagayo, su zona de influencia y las Áreas Marinas Protegidas que se encuentran en dicha zona, con especial énfasis en el estado ecológico de las poblaciones de especies en peligro de extinción. 


\section{Conclusiones}

Lo que realmente destaca el Proyecto Turístico Golfo de Papagayo y su régimen legal específico es que se trata de un desarrollo planificado, es decir, con un Plan Maestro que a pesar de responder a otros instrumentos de planificación y política nacional más macros cuenta con un apoyo y direccionamiento por parte de representantes del sector público y privado que lo enriquece e incide en que se destaque por encima de mucho otros.

Paralelo a ello, el proyecto se encuentra bajo la administración y supervisión estatal, no así de las Municipalidades, sino del Instituto Costarricense de Turismo que ejerce sus competencias en el área sin perjuicio de las otras responsabilidades asignadas en materia de recursos naturales y patrimonio natural del Estado al Ministerio del Ambiente y Energía.

Por último, al ser sujeto de una declaratoria de utilidad pública y ser reconocidos de conveniencia nacional, logran incidir más profundamente para lograr una mayor colaboración y coordinación por parte de las instituciones públicas con ingerencia en la gestión de dicho espacio.

\section{RESUMEN}

El Golfo de Papagayo, Guanacaste, Costa Rica, es la región de mayor desarrollo turístico en el país. El Proyecto Turístico Golfo de Papagayo (PYGP) es producto de un estudio que contrata el Banco Centroamericano de Integración Económica (BCIE) para analizar el potencial turístico de Centroamérica. Dicho proyecto comienza a gestionarse en 1982 y se exceptúa de la administración Municipal siendo competencia del Instituto Costarricense de Turismo (ICT). El PYGP pretende un desarrollo planificado mediante un Plan Maestro que es administrado y supervisado por el Estado. El proyecto fue declarado de utilidad pública y de conveniencia nacional, lo cual le da más peso y mejores posibilidades de desarrollarse. Con su plan maestro establecido desde 1995 que determina los lineamientos generales y su legislación específica este proyecto se ha llevado a cabo a lo largo de estos años como una oportunidad para Guanacaste y para Costa Rica.

Palabras clave: Régimen especial, excepción de la zona marítimo terrestre, zona pública, Papagayo, Bahía Culebra, Costa Rica. 